\title{
A Laboratory-based Course in Systems Engineering Focusing on the Design of a High-speed Mag-lev Pod for the SpaceX Hyperloop Competition
}

\section{Dr. Dominic M. Halsmer P.E., Oral Roberts University}

Dr. Dominic M. Halsmer is a Professor of Engineering and former Dean of the College of Science and Engineering at Oral Roberts University. He has been teaching science and engineering courses there for 25 years, and is a registered Professional Engineer in the State of Oklahoma. He received BS and MS Degrees in Aeronautical and Astronautical Engineering from Purdue University in 1985 and 1986, and a PhD in Mechanical Engineering from UCLA in 1992. His current research interests involve affordance-based design and systems engineering, reverse engineering of complex natural systems, and the preparation of scientists and engineers for missions work within technical communities.

\section{Prof. Robert P. Leland, Oral Roberts University}

Robert Leland has taught engineering at Oral Roberts University since 2005. Prior to that he served on the faculty at the University of Alabama from 1990 - 2005. His interests are in control systems, engineering education and stochastic processes. He has participated in engineering education research through the NSF Foundation Coalition, NSF CCLI and NSF Department Level Reform programs.

\section{Emily Dzurilla}




\title{
A Laboratory-based Course in Systems Engineering Focusing on the Design of a High-speed Mag-lev Pod for the SpaceX Hyperloop Competition (Work in Progress)
}

\begin{abstract}
A new course has been developed for undergraduate engineering students that enhances their understanding of the multidisciplinary aspects of systems engineering. Students pursing a general engineering degree with concentrations in mechanical, electrical, and computer engineering are collaborating to develop a prototype for a high-speed, magnetically-levitated transportation pod for the Hyperloop Competition, recently commissioned by Elon Musk of SpaceX Corporation. This project is an excellent opportunity for students to engage in a hands-on, real-world, multidisciplinary design experience that lends itself to the application of systems engineering principles.
\end{abstract}

Systems engineering principles are presented and discussed in class, and the students are periodically examined over this material. However, most of the students' time and effort is spent outside of class, applying this information as they develop the prototype in the engineering laboratory. An industrial setting is simulated by breaking the students into subsystem development teams that must work together to not only successfully develop their own subsystems, but ultimately integrate these subsystems into the final complex system that meets all the requirements. Formal documentation and presentations at the end of the course serve as a Critical Design Review. Qualification testing is also conducted to verify both subsystem and integrated system performance. Final qualification testing is conducted at the SpaceX test facility in Hawthorne, California.

In addition to the technical aspects of the project, students also learn about systems engineering management, customer and contractor relations, and system life cycle considerations. They meet regularly with technical advisors and submit weekly progress reports, emphasizing how their subsystem interfaces and interacts with the rest of system. This is necessarily a multidisciplinary effort since the prototype consists of integrated subsystems that are mechanical, electrical and computational in nature. The final project report includes a section where the students are encouraged to reflect on the quality of their experience as it pertains to their understanding of systems engineering. Student surveys are also conducted in an effort to assess the impact of the course and elicit feedback on how the course may be improved. 


\section{Previous Design Explorations in Engineering Education via Systems Engineering}

Courses involving integration and testing of complex hardware systems are not new to engineering education. In 2012, faculty at St. Louis University reported on a systems engineering course where students gained hands-on experience with the development of a small satellite. They claim, "It is very important to use real hardware for practicing the integration \& test steps and for motivating students." The following four themes were maintained throughout this course to guide and encourage students in the development process: 1. Physics is actively opposed to spaceflight, 2. Nothing ever works the first time you put it together, 3 . There is never enough time or money, and 4. Fear [of failure] rules all decisions. They suggest that, 'Our "four heuristics of space systems" were a very successful method for engaging the students with the material, and can be applied to other parts of the design lifecycle or to other aspects of engineering. ${ }^{1}$ These heuristics were found to be equally applicable in the development of a nextgeneration ground transportation system, which is the project of interest in the current paper.

A course in which students applied systems engineering principles to a lunar mining robot project was described at the 2013 ASEE conference. The authors argue for the "inclusion of systems engineering in university-level capstone curricula to improve engineering design." Although this project involved an intense competition, it was limited to paper designs, which lacked the realism of hardware-intensive projects. The claim made in the previously cited study about the importance of real hardware was found to ring true.

Just last year, a couple of engineering educators from California made the case for integrating systems engineering into senior design. They claim that the traditional sequence of courses in most mechanical engineering curricula "creates a gap in students' understanding of systems level requirements." "Their proposed remedy involves the introduction of the Systems Level Diagram (SLD) early in the senior design course. This assists the students in handling issues that arise at the interfaces between subsystems. This approach was actually developed by graduating mechanical engineering students who found the SLD useful in their pursuit of the SAE Aero Design Competition. It proved to be instrumental during the synthesis, tradeoff, analysis, fabrication, assembly, and testing phases of the project, and led to a substantial gain in the students' systems-level understanding.

\section{Impetus for a New Kind of Engineering Course}

A few days before the start of the fall 2016 semester, it became clear that a solution was desperately needed for a pressing problem that was facing the Oral Roberts University (ORU) Engineering Program. Almost a year earlier, a few of our undergraduate engineering students had initiated an effort to pursue Elon Musk's Hyperloop Design Challenge. This competition entailed the development of a transportation pod prototype that would serve as a technology 
demonstrator for the next generation of high-speed ground travel. The students were very successful in the early stages of the competition, and were ultimately invited to participate in the final round of the competition involving 30 other teams that was scheduled for the end of January in 2017. Both students and faculty were very excited about this opportunity to demonstrate their engineering prowess. The problem was that there was much engineering work left to be completed on the project, and there were not enough students and faculty committed to the work. In addition, the students who were committed to the project did not have enough time in their busy schedules to satisfactorily complete the prototype. As the situation was discussed in a faculty meeting two days before the start of that fall semester, an idea began to form in the mind of a faculty member who is also the primary author of this paper.

Having had seven years of experience in the aerospace industry with Hughes Aircraft Company, Space and Communications Group, working in the area of satellite dynamics and control systems, this author suggested that a laboratory-intensive course might be initiated for the fall semester in the area of systems engineering. Students taking this course would learn about systems engineering while focusing on the completion of the prototype for the Hyperloop competition. Indeed, since the prototype was envisioned to be a complex integration of multiple mechanical, electrical, and computational subsystems, it would serve as an excellent vehicle in which to illustrate the principles of systems engineering. The course would serve as a technical elective for juniors or seniors in the mechanical, electrical or computer engineering concentrations of the general engineering major offered at ORU. After some discussion, it was agreed that the proposer should immediately begin preparing to teach this course.

The course turned out to be more popular than expected as a total of nineteen students from all three concentrations enrolled during the first week of classes that fall semester. This is an aboveaverage sized junior/senior level class for our program. Based on anecdotal feedback from students, it is clear that several students were influenced to join the Hyperloop team as a result of this new course. The class met twice per week to receive a brief lecture on principles of systems engineering, based on books by Faulconbridge and Ryan. ${ }^{4,5}$ The classroom was located in the immediate proximity of the laboratory where the prototype was being built, which made it convenient to engage with hardware and testing elements before, after, and even during classes. This was advantageous since the students were required to spend at least 6 hours per week outside of class developing the prototype. Weekly progress reports detailing this effort were also required from every student. These reports included a description of specific items that were addressed, and the amount of time spent on each item. Near the end of the course, both oral and written final reports were required from each student, detailing their total contribution to the effort. Grades were assigned based on a weighted average of exam scores, progress reports and final reports. Another faculty member (second author of this paper), who had been overseeing the project from its inception, served as primary technical advisor. 


\section{Replicating an Industrial Setting}

One of the advantages of a small, close-knit general engineering program is the ease with which students within all three engineering concentrations (mechanical, electrical, and computer) can work together on multidisciplinary problems. This ended up being a huge advantage during development of the Hyperloop pod prototype. Since students from all three concentrations were enrolled in the systems engineering course, their combined areas of expertise went a long way toward covering the subsystems that were currently under development for the project.

Within the first week of classes, a briefing was held to orient the students to the current status and design of the prototype. Some preliminary design work had been conducted on the project, but hardly any detailed design, and construction had not yet begun. At the end of the briefing, the various subsystem areas were described and students were invited to join the effort on the development of a particular subsystem, and the integration of that subsystem with the rest of the planned system. Students naturally gravitated toward areas of their own expertise and interest, where they could contribute the most. With the help of the student project leader and the faculty technical advisor, subsystem team leaders were chosen to direct the efforts on each of the subsystems.

Since the current design involved a magnetically levitated high-speed pod to be operated in a near-vacuum environment, the various required subsystems represented several diverse and challenging areas. These subsystems consisted of structures (or chassis), wheels and axles, magnetic levitation, hydraulic braking, magnetic braking, cooling and thermal control, stability and controls, power, communications, information processing, sensing, and aerodynamics. Only about 30 students contributed to the development of the prototype, so the subsystem teams were relatively small, averaging about 2-3 students per team.

As the students learned how systems engineering projects are conducted in industry, they began to naturally replicate industrial settings and behavior in the classroom, conference rooms, and laboratories. Early on in the project, they began to understand and appreciate the importance of planning for thoughtful subsystem integration, the incorporation of all the interconnected subsystems into the final complete and functional prototype. Communication between subsystem teams occurred regularly in an effort to make sure that there were no surprises during integration and testing. Often, students in the mechanical, electrical and computer engineering concentrations were seen working together on subsystems that involved two or more of these areas, or working on the interface between subsystems from two or more of these areas. It was very gratifying, from the perspective of a faculty member with systems engineering experience, to see how well the students were able to replicate an industrial setting. This is one of the primary goals of the educational process that contributes to the success of graduates in industry. 


\section{Detailed Design and Results}

In 2013 Elon Musk published a white paper proposing a new form of transportation, the Hyperloop, which would travel inside an evacuated tube at over $700 \mathrm{mph}$ and travel from Los Angeles to San Francisco in about 30 minutes. ${ }^{6}$ In July of 2015, SpaceX announced the Hyperloop Pod Competition. University students and others would design pods, or vehicles, for the Hyperloop. After filtering down 1200 entries, 76 teams presented their designs to SpaceX and Tesla engineers at Texas A\&M in January of 2016. Of these, 31 teams were selected to build their pods and bring them to SpaceX Headquarters in Hawthorne, CA, to compete on a one mile test track. ORU's Team Codex was one of these groups. Each team was assigned two SpaceX engineers as mentors. Ultimately 27 teams came to SpaceX in January 2017 to compete on the track. The competition was actually based on the design, and performance on the track was just one item on the scoresheet.

On the test track, a SpaceX pusher would accelerate the pods up to speed, perhaps with additional propulsion from the pod. Then the pods would coast and eventually apply a braking system for deceleration. In general, three approaches were taken, and these were all accommodated by the SpaceX test track. The track has a concrete floor, a central aluminum Ibeam (6061) and aluminum plates on each side (6101). Following Musk's original white paper, some of the pods used air bearings, similar to an air hockey table. For the competition, this meant carrying tanks of compressed air, and operating with fairly small tolerances. Some pods used wheels, which are better for turns (although the test track is straight). The use of wheels has challenges, since it requires contact at high speed. Most of the groups used some form of magnetic levitation. Several groups used rotating magnet wheels, or hover engines, from Arx Pax Corporation.

Team Codex and many other groups used the Inductrack approach, in which stationary permanent magnets provide lift when accelerated past a minimum speed. This approach is relatively inexpensive, eliminates the need for large, heavy, expensive and potentially explosive batteries, is dynamically stable, and is non-contact. Like many other groups, Team Codex also used permanent magnets for eddy current braking by moving these magnets closer to the flange of the I-beam. Permanent magnets were also used on both sides of the web of the I-beam for lateral and yaw control. Pods also needed to be designed for emergency braking in the event of a total power failure. However this braking must be disabled while the SpaceX pusher is accelerating the pod. Figure 1 is an illustration of the Team Codex pod. 


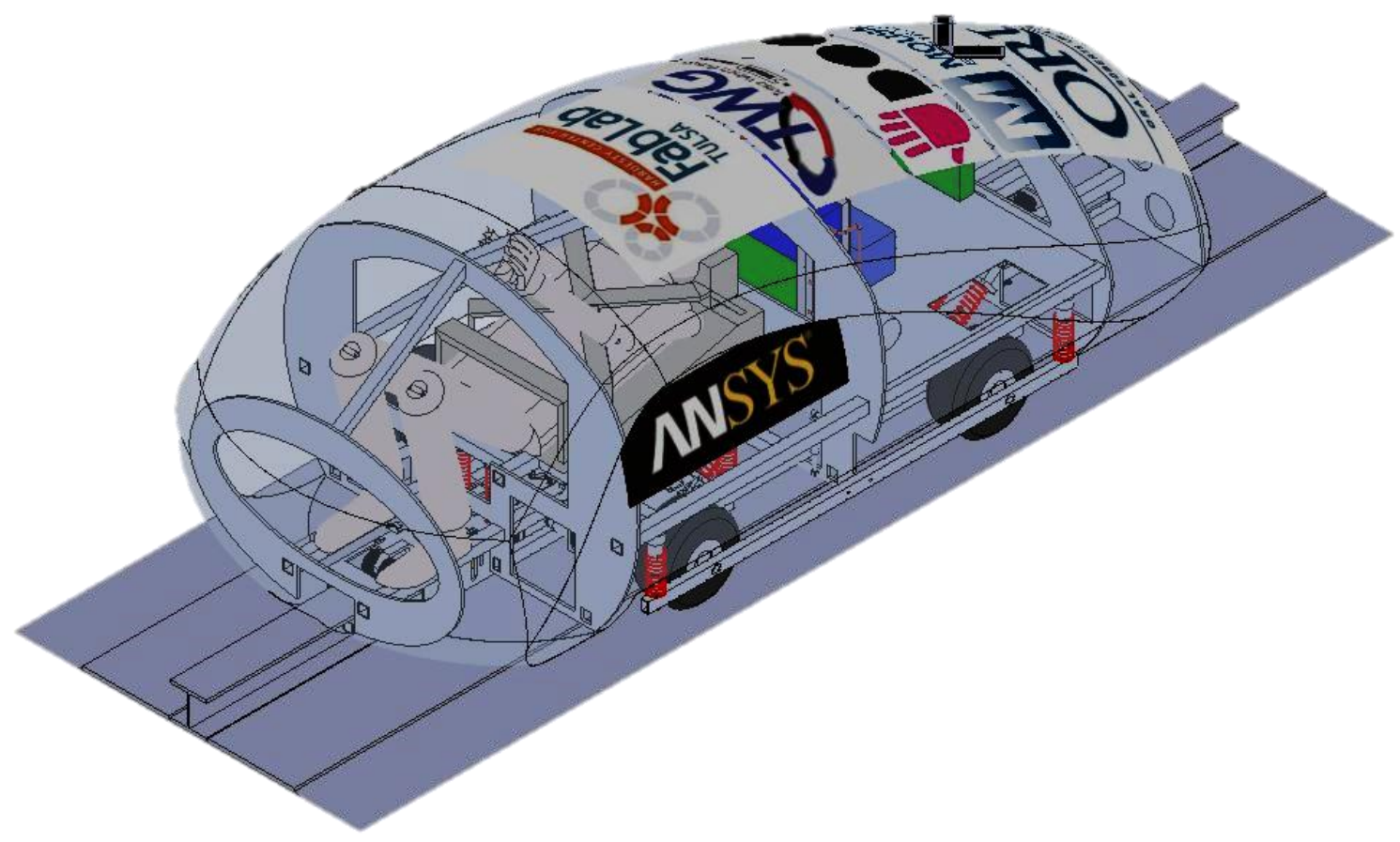

Figure 1. A version of the pod, showing the concrete sub-track, aluminum plates, I-beam and wheels.

At the competition, pods needed to pass a series of tests to be able to run on the test track. They needed to be checked for fit on the I-beam. They needed to be tested in a large vacuum chamber while powered on. They needed to be tested on a short outdoor track at speeds of about $25 \mathrm{mph}$. They needed an easily accessible GUI for monitoring the health of the pod. They needed to pass a software check, taking the pod through its state diagram. Only three teams were permitted to run in a vacuum on the test track: MIT, Delft and Technische Universitat Munich (WARR). These teams all used magnetic levitation. These were tested at 50-60 mph, and the WARR pod made it all the way down the track and was viewed as the top performer.

Needless to say, none of the material in the paragraph above is covered in standard undergraduate engineering classes, so the students had a big learning curve. Two critical design areas were magnetic levitation and magnetic braking. These were approached based on available theory, simulation using ANSYS Maxwell (provided to all the teams by ANSYS), and experiment. For experiment the team set up a 32 inch aluminum disk, machined by our industrial partner TWG to match the thickness of the I-beam flange. The disc could be rotated at high speed so the outer edge could reach speeds of $300 \mathrm{mph}$. In general, theory, simulation and experiment did not always agree, so the experimental results were used in the design. SpaceX also asked the team to delineate what was based on experiment, and what was extrapolated through simulation, showing a strong preference for experiment. Structural joints were tested by applying weight and measuring deformation. The electronics were tested in a vacuum chamber, 
pumped down to $0.5 \mathrm{psi}$, and monitored for heating. Test coupons of composite materials for the shell were also made and tested for bearing static loads. Testing of the torques available from the stepper motors used on the pod was also critical to ensure the motors and gearboxes would be adequate.

Students in the class were divided into teams working on different areas of the pod: structures, wheels and disk brakes, magnetic brakes, magnetic levitation, cooling, electronics/computation, and the shell/composites. Most teams included additional students who were not enrolled in the systems engineering class. This often required that students in the class pass along helpful systems engineering concepts to other team members, which provided an additional boost to learning. Throughout the design process it became clear that the actions of one group affected other groups. For example the dimensions of the magnetic levitation system, used at high speeds, had to be consistent with the dimensions of the wheels, used at low speeds. Non-interference between the structure, levitation and magnetic braking system was also necessary.

The structure was modified several times to accommodate and support the wheels, levitation and magnetic brakes. Redesigns of the structure and cooling systems that reduced weight impacted the requirements of the braking and levitation systems. The shell had to be designed not only to fit the dimensions of the structure, but be easily attachable and removable. Students in different groups also needed to negotiate real estate on the pod where their subsystems would reside. Several meetings of the larger group (30 students) were held and students reported their group's progress. This was helpful in coordinating the different groups, and providing a better educational experience for all the students. Due to the interactions of the different subsystems on the pod, the different groups also needed access to the most recent designs and CAD files. An online database of design changes was established, but perhaps not completely utilized.

\section{Lessons Learned and Student Feedback}

In retrospect, from the perspective of the faculty technical advisor, these ideas would have been beneficial to the project, and would be implemented in the future if a similar design opportunity arises:

1. Have each group submit a schedule with milestones of what they would accomplish, and submit a plan to catch up if they fall behind.

2. Have each student report actual accomplishment in addition to time spent on a topic.

3. Conduct more frequent design reviews.

Students in the Systems Engineering course also shared some insights that they gained from participating in the project. The following comments are illustrative, and were received as part of their final written project reports for the course, about seven weeks before the final competition at the SpaceX facility in California. 
"The journey from the start of the semester until now has been very exciting, daunting, challenging, and eye opening. The challenge of cooling the ORU pod while it travels through a vacuum was a complex problem indeed, and took hundreds of hours of research, calculations, experimentation and design. But in the end, we achieved what we had aimed to do: design a cooling system that is practical, affordable, effective and easy to manufacture."

"One of the most rewarding parts of the whole project and the class is the hands-on learning that I've been able to achieve... Not only has it been great to experience first-hand the topics that we are learning in the lecture, but it has been great to learn from the construction and design process... Throughout this semester I have made sure to ask plenty of questions to try and understand all of what we are working with and working on... This project helped change the old mentality that I had where if I did not understand something, then I would feel underqualified and unable to contribute towards anything. It has changed it to where now I have the desire to learn what I can despite a lack of experience or understanding in order to increase my own knowledge and work as much as I can with what is in front of me. This class and project has been very worthwhile and I hope that we are able to finish the pod in time and represent well at the competition in January."

"I am enjoying working on this project and look to learn more about evaluating and designing something that has not been put to practice in the public transportation system here in the U.S. yet...my role on the team has been more of a Test Engineer. I have been performing hands on tests with certain components that will be placed within the pod. This coexists with the testing/evaluation phase inside the systems engineering book where engineers get to test the prototype and evaluate certain areas/flaws to it; should they be replaced or even redesigned? I think this role suits me more as I am a hands on person and hopefully in the future I get a job to test all the up and coming things designed by a company for daily use."

"The Systems Engineering class has been quite an adventure... I have greatly enjoyed working on the Hyperloop, and am impressed by what all we have accomplished. I will continue to work diligently to complete the task at hand and celebrate tremendously when it is all finished. I pray that all of our hard work pays off."

"Over the course of this semester, we have made a significant dent in the progress of the Hyperloop, and we will continue to work as hard as we can to accomplish this project on time! We have seen many benefits in applying systems engineering techniques to both our sub-division team and Team Codex. We have learned about the necessary stages of thought in making sure to look at the big picture requirements before designing subsystem requirements, as well as finding the appropriate time to start building prototypes and manufacturing. It is great to see the applications of systems engineering." 
"This year I learned many things. Not only about how a system of people work together and the processes in which something should be built, but also how to take that information from lecture into my actual daily life when working on projects... Systems Engineering class has brought on a new perspective to project building. The class has given me the knowledge on project manufacturing: from the design phase, all the way through to the final product. As the building phase approaches quickly, I get excited to see the material in class portrayed to physical work in the machine shop."

"All in all, it's been a very busy semester with all the work we've been putting in. I've been a part of a lot of design when it comes to the brake array and have had to do lots of calculations and math to figure out what forces we can be expecting and what length to make various different items. I've gotten to do some machining and assembling of our system which has been pretty fun and I know I'll be doing a lot more as we move into the build phase of this design...I've learned a lot about design and implementation this semester and am proud of the work my team has accomplished."

"I was given the task of managing the electrical and computer teams. To get the work done as fast as possible, I divided the manpower into different teams. I assigned each member into the teams based on their concentration and experience. Each team had specific tasks that I had assigned to them to get done. I knew that I would not be able to oversee all the teams and so I chose leaders out of the teams who I thought had experience and leadership skills. I set weekly goals and deadlines for each team."

"Overall, I have really enjoyed this project. It has been good to get hands on experience in electrical engineering. And I very much enjoyed when I got to make an entire electrical design in OrCAD. There were many times it seemed like there wasn't much for me to do, and what I was supposed to do could not yet be done. But I just needed to find something else to do that would be useful. And for the most part, what I did in that time where there wasn't much to do, ended up being helpful. And even if it didn't further progress in the electrical part of the project, it did further my understanding of the project. This understanding even helps to prepare you to make better progress when it is possible, whether that was by doing research or helping other teams. I feel it is good to not only make progress for your individual team, but also to learn as much as possible throughout the process and contribute to the project as a whole. And as time permits, understand every aspect of what you are doing as well as possible, which I was able to do by doing research throughout the project."

"Overall, I worked about 203 hours on the Hyperloop this semester. I also plan to stay over Christmas break to help with the manufacturing and construction of the pod. This has been a great project so far and I have had fun working with so many people on this team. It has also 
been great working on levitation, experimental testing, and simulations because it has given me a lot of experience in various aspects of the project. Lastly, systems engineering has given me some great insights and procedures to use moving forward in future projects."

"As a whole, the assignment of a specific system in a system of systems (SOS), has taught me a lot about how a complex system is created, as well as how difficult it is to adjust each system in coordination with others changing as often as they do. A system such as the magnetic braking system has been affected more than I could have imagined by each detail of the surrounding systems. I have learned a tremendous amount about system design as a whole, and about the many steps a system must undergo before it is launched into any field. This class has added a great amount of depth to engineering and has definitely changed my perspective on engineering for the better."

And finally, from the perspective of the Student Project Leader,

"The team became much easier to manage as a result of the class. Each of the students thought more about the project as a whole, instead of only considering their own subsystems during the design process. This made system integration much easier than it had originally been. As a product of this kind of thinking, communication between team members working on different subsystems greatly improved. They realized that to have a functional pod, everyone had to have some level of technical understanding of the other subsystems that their design would interact with. It became much easier to manage a team that internally recognized the importance of proper communication. The enhanced communication improved things for the student team leader, as problems could be solved through communication of the subsystems, instead of taking every confusion to the leader. The class also simplified ascertaining the status of the project by classifying the process into the stages presented in the textbook. The next steps for the project became clear, which made it easy to instruct the different subsystem teams on their next actions."

\section{Conclusions from the Perspective of the Course Instructor}

Analysis of student feedback from the previous section highlights how this course and project provide several important advantages for engineering education. The students were genuinely excited about completing a challenging, cutting-edge project that pushed them beyond their "comfort zones" into new areas of learning. They really appreciated being able to build what they were designing, and seeing how this influenced the design process. They were more motivated to engage and find answers to hard questions. They were able to make application of systems engineering principles on a real project with real consequences. As a result, they realized the benefits of the systems engineering approach. They were motivated to work through teamwork and management issues in order to achieve successful system development. And finally, this experience opened their eyes to career paths in systems and test engineering. 
The student progress reports, test scores, survey results, and final oral and written project reports all seem to indicate that the lab-oriented format for this course was very successful in communicating the principles of systems engineering to this group of students. In addition, having now successfully completed the prototype and participated in the competition at the SpaceX facility in California, this team has demonstrated that they have the engineering knowledge and ability to develop a complex system such as the Hyperloop pod. I have been extremely impressed with the motivation and accomplishments of this group. In my 25 years as an instructor of undergraduate engineering courses, I have not seen a group of students develop such a complex prototype in so little time, and with such minimal resources. Their status as finalists in the Hyperloop competition serves as an inspiration to other students, and has already attracted additional prospective students to our engineering program. I expect it to feature prominently in our promotional materials over the next few years.

The format of this course was a significant departure from this professor's standard operating procedure. Prototype development involving various stages of design, construction, and testing replaced the normal barrage of homework problems from the back of the textbook. Some apprehension was experienced by both instructor and students at the start, as the students wrestled with the open-endedness of the project and all the associated sub-tasks. But as the students began to engage with, and work through each of these challenges, something wonderful happened. I realized that we had effectively reproduced the work setting that I had experienced during my years in the aerospace industry at Hughes Aircraft Company. The student subsystem teams were serving as various departments within the project development office. They were responsible for various aspects of the prototype, but meeting regularly with other areas to ensure proper integration and functionality. Toward the end of the course, as integration became the pressing issue, the students successfully made the transition from subsystem engineers to systems engineers; no longer just concerned with the performance of their particular subsystem, but with the success of the prototype as a whole.

This reproduction of an industrial setting has many benefits beyond instruction in systems engineering. Students learned how to effectively work as teams, how to handle management and personnel issues, how to communicate well in a technical multidisciplinary environment, how to manage time and resources effectively, how to interact with customers and subcontractors, how to plan ahead to meet deadlines and delivery dates, and how to prepare for, and conduct themselves at, a high-level competition. As they developed these skills, the students became more comfortable with the idea that, within a few short months, they would take their rightful place as engineering graduates in graduate schools, engineering firms and companies around the world. In short, they began to see themselves as practicing professional engineers. This is probably one of the most valuable outcomes of this course. Given the right opportunity, I would 
teach this course again, or another course using a similar format. What it lacked in structure, it more than made up for in its breadth and depth of industrial-type experience.

\section{Bibliography}

1. Swartwout, M. A., \& Jayaram, S. (2012, June), Spacecraft Integration and Test: An Undergraduate Course in Systems Engineering Practice Paper presented at 2012 ASEE Annual Conference \& Exposition, San Antonio, Texas. https://peer.asee.org/21927

2. Guerra, L., \& Murphy, G. A., \& May, L. D. (2013, June), Applying Systems Engineering to the Lunabotics Mining Competition Capstone Design Challenge Paper presented at 2013 ASEE Annual Conference \& Exposition, Atlanta, Georgia. https://peer.asee.org/19217

3. Youssef, G., \& Arutyunov, V. (2016, June), An Approach to Integrating Systems Engineering into Senior Design Paper presented at 2016 ASEE Annual Conference \& Exposition, New Orleans, Louisiana. 10.18260/p.26569

4. Faulconbridge, Ian, and Ryan, Michael, Introduction to Systems Engineering. Argos Press, 2015, ISBN 978-1-921138-08-9.

5. Faulconbridge, Ian, and Ryan, Michael, Systems Engineering Practice. Argos Press, 2014, ISBN 978-1-921138-07-2.

6. Musk, Elon, "Hyperloop Alpha”, 2013.

www.spacex.com/sites/spacex/files/hyperloop_alpha.pdf . 